\title{
Frequency control ancillary service provided by a wind farm: dual-BESS scheme
}

\author{
Dailin YAO ( $ه)$, San Shing CHOI, King Jet TSENG, \\ Tek Tjing LIE
}

\begin{abstract}
Network frequency control function is incorporated into a grid-connected wind farm-dual battery energy storage system (BESS) scheme. The design of the scheme takes advantage of the rapid response characteristics of the BESS and the in-built short-term overloading capability of the associated power conversion devices. A control strategy to regulate the BESS output power is then proposed. It is shown that the frequency control action offered by the BESS complements amicably with that of conventional generators in enhancing the frequency regulation attribute of the grid system.
\end{abstract}

Keywords Battery energy storage systems, Wind power generation, Frequency control ancillary service

\section{Introduction}

One major impediment to the large-scale penetration of wind generation into grid systems is due to the concern on its impact on the network security and quality. Depending on the extent of the fluctuations in the generated wind power, variations in network frequency and voltages could reach unacceptable levels if appropriate corrective actions

\section{CrossCheck date: 16 March 2014}

Received: 9 November 2013/Accepted: 21 March 2014/Published Online: 5 May 2014

(C) The Author(s) 2014. This article is published with open access at Springerlink.com

D. YAO, S. S. CHOI, K. J. TSENG, Center for Smart Energy

Systems, School of Electrical and Electronic Engineering,

Nanyang Technological University, Singapore 639798,

Singapore

(凹) e-mail: yaod0002@e.ntu.edu.sg

T. T. LIE, Auckland University of Technology,

Auckland 1102, New Zealand are not taken. Indeed, satisfactory power quality can be achieved as part of an ancillary service offered by the generators through the trading of real and reactive powers, as explained in $[1,2]$.

With the above considerations in mind, a dual battery energy storage system (BESS) scheme to alleviate the impacts of wind generation on grid systems has been proposed in [3]. The scheme involves the application of two identical BESS modules, denoted as BESS Module 1 and BESS Module 2 in Fig. 1. Each BESS module is interconnected to a DC/DC converter of the same capacity. In the figure, BESS Module 2 is shown being charged by the wind turbine generators (WTG) and the BESS module is said to be in the stand-by mode where the WTG could represent a cluster of wind turbine generators in a wind farm. The charging power is denoted as $P_{c}$. Concurrently, the so-called in-service BESS (BESS Module 1 in this instance) is discharging power to the AC grid. The two BESS will interchange their roles when BESS Module 1 is unable to sustain the delivery of the scheduled power due to, for example, the battery low state of charge (SOC). BESS Module 2 will then take over the in-service role by supplying energy to the grid while BESS Module 1 is in turn to be charged by the WTG. In this manner, the dualBESS scheme has allowed the unsteady input wind power dynamics to be decoupled from the grid.

Comparison of the dual-BESS scheme with other schemes shown in the literature has been included in [3]. The proposed scheme is to participate in power market operation and is based on the assumption that deep-cycle batteries have been used. As reported in [3-5], the advantages of the proposed dual-BESS scheme can be summarized as follows:

- Allows the wind generation to participate in the power market and makes a firm commitment on its dispatch;

- Profit optimization is also achievable; 


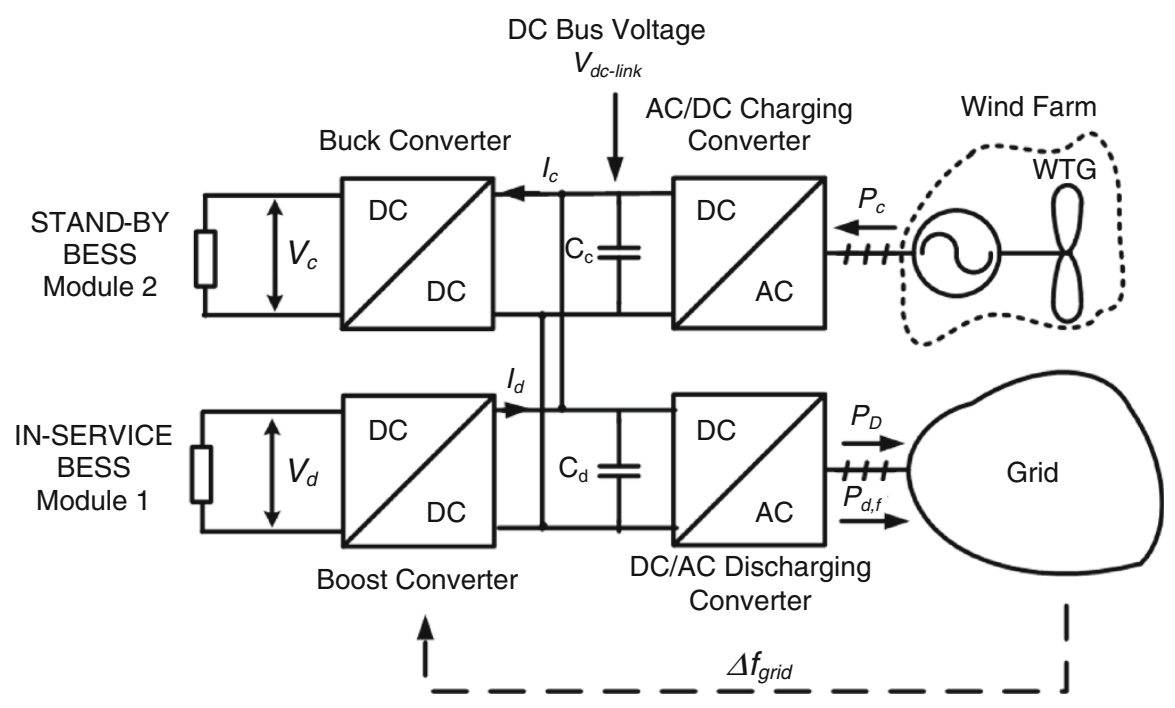

Fig. 1 Schematic of the proposed wind farm-dual BESS scheme inter-connected to grid

- Battery lifetime can be better estimated as the BESS are designed to operate in full charge-discharge cycles;

- The charging/discharging process of the BESS can be flexibly controlled by this scheme.

The study in [3] focuses on proposing a method to schedule the dispatched power of the wind farm-dual BESS scheme, so as to meet the prevailing power market requirements. However, various studies have shown that BESS is an excellent power system asset for providing system frequency regulation function [6-11]. Indeed frequency regulation is even recognized as the most profitable application of energy storage in power system [12]. It is in the context of providing frequency control that the proposed scheme has excellent potential. The variable nature of wind has often resulted in the dispatched output power of the dual-BESS scheme at levels much less than the rated power of the wind farm/converters. Therefore, the capacity margin between the dispatched power and the rated power of the converters can be used to support the frequency regulation function: an ancillary service which is also profitable to the wind farm operator, in addition to the sale of the dispatched power [1].

This paper investigates the possibility of applying the dual-BESS scheme for providing frequency control service, while the basic function of power dispatching is still being taken into consideration. The frequency regulation service provided by the dual-BESS scheme is described and compared with other schemes in Section 2. By extending the well-established conventional frequency control system model to include the wind power dual-BESS scheme, the design of the dual-BESS scheme for frequency control is then shown in Section 3. Section 4 demonstrates that the capacity of the discharging converter can be reduced by capitalizing on the short-term overloading capability of the

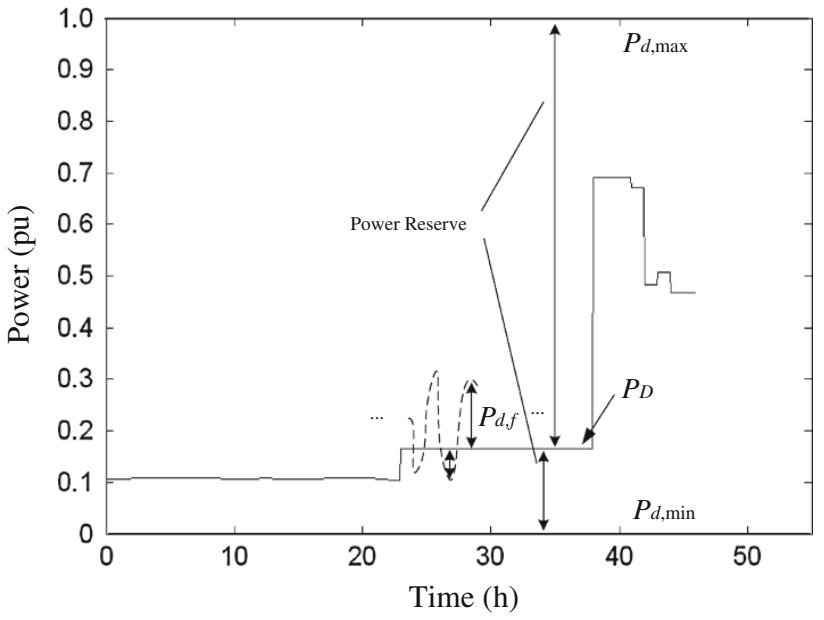

Fig. 2 Dispatch and reserve power: BESS power rating is assumed to be $1 \mathrm{pu}$

converter. Several illustrative examples are then presented in Section 5. The main findings are summarized in Section 6.

\section{Role of the dual-BESS scheme in network frequency regulation}

As explained in Section 1, the main motive of the proposed dual-BESS scheme considered in [3] is for the wind farm to achieve comparable level of power dispatchability as that of a conventional power station. The frequency control function discussed in the present paper is to be added as an ancillary service offered by the wind farm-BESS power station.

\subsection{Proposed frequency regulation scheme}

With reference to Fig. 2, power reserve of the wind farm-dual BESS scheme is defined as the ability of the 
scheme to supply power higher or lower than the scheduled level $P_{D}$. Interested readers may wish to refer to $[3,4]$ to understand how $P_{D}$ is determined. In the present investigation, the dual-BESS scheme is to operate as a power reserve source as well: in response to the grid frequency deviation $\Delta f_{\text {grid }}$ as shown in Fig. 1, a command shall be generated to adjust the output power of the in-service BESS. In this manner, the dual-BESS scheme will not only meet the power schedule but also provide the frequency regulation service. This would be possible provided that the sum of the net level of $P_{D}$ and the frequency regulating power component, denoted as $P_{d, f}$ in Fig. 2, does not exceed the discharging converter rating. In this way, the wind farm dual-BESS scheme functions in a manner similar to a conventional power station in providing frequency regulation ancillary service.

There is, however, a distinct difference between the dual-BESS scheme and a conventional wind farm. In [3], the authors have attempted to match the behaviors of the in-service and standby BESS when designing the dispatch strategy for the dual-BESS scheme. The final outcome is that when the state of charge (SOC) of the in-service BESS is approaching its lower limit, the SOC of the stand-by BESS shall reach its maximum level. In this way, the total amount of stored energy in the two BESS is approximately equal to the capacity of a full BESS. This unique feature of having one full-BESS reserve capacity is observed even though the wind farm output is totally weather-dependent. As the capacity of the BESS is designed in [3] to cater for power dispatch purpose, typically the amount of stored energy is sufficient to sustain the BESS full power discharge for several hours. Thus the dual-BESS scheme shall have more than adequate reserve in providing primary frequency control function for grid systems. For instance, under the jurisdiction of European Union for the Co-ordination of Transmission of Electricity (UCTE), or its recent replacement ENTSO-e, generating units are required to sustain for 15 minutes on primary frequency control [9]. While such technical criteria could be subject to regular review, the intent of this paper is to adopt this frequency support requirement to illustrate the proposed approach.

An important observation is concerning the frequency regulation ability of the dual-BESS scheme: the regulating task is most strenuous when $P_{D}$ is high while wind generation is at the maximum. In this instance and in accordance to the dispatch strategy of [3], the scheduled dispatch power of the wind farm is likely to approach the boost converter power rating. Therefore, there is only a limited amount of spare converter capacity for the BESS to use in regulating system frequency. Furthermore, reserve power of other generating units in the grid also tends to be low too under this high load demand period. This will place a limit on the frequency regulation ability of the dual-BESS scheme.

\subsection{Comparison with other schemes}

Much recent research attention has been directed towards frequency regulation by using the stored kinetic energy in the wind turbines [13-17]. The main drawback of this approach is that the wind turbines have to operate at speeds which will not allow the maximum harnessing of energy from the wind.

Alternatively, the use of battery energy storage systems for primary frequency control has been studied by many researchers [6-11] and different BESS schemes have been adopted. For instance, the authors in [11] consider the installation of two BESS in different locations of an isolated power system. During a sudden demand change, the two BESS are to share portions of the load change based on their rated capacity. The configuration and operation of their system are fundamentally different from the dual-BESS scheme examined in the present investigation.

The BESS schemes in [8] and [9] use single BESS to achieve frequency regulation. The BESS capacity may not be enough to absorb or discharge power because of the practical limit placed on the SOC of the BESS. The proposed dual-BESS scheme does not encounter such a problem. Furthermore, the operational strategies of the BESS in $[8,9]$ are such that the schemes commit a fixed amount of stand-by power reserve. Also unlike $[8,9]$, the power reserve in the dual-BESS is not committed for the long term. As proposed in [3], the dispatch power of the dual-BESS is traded in a daily power market. Therefore, its capability to provide frequency regulation varies with the scheduled $P_{D}$.

Generally, when the frequency regulation is considered as an additional function of the energy storage scheme, it would pose additional constraints on the design of the control strategy. The authors of [10] propose the use of batteries in parked electric vehicles (EV) to contribute to the grid frequency regulation, an ancillary function similar to that offered by the dual-BESS scheme. The grid connection is to charge up the EV batteries within a specified time. As such, the EV should be readily charged within a duration set by the customer, whereas in [3], the committed dispatch power of the dual-BESS shall be guaranteed. Apart from the similarity on the constraints when treating frequency regulation as an ancillary function, the EV scheme takes the form of distributed energy storage control: thus, the optimization of the vehicle owner benefits distinguishes the EV operational strategy from that of the dual-BESS scheme. 


\section{Control system design for frequency regulation}

Fig. 3 shows the load-frequency regulation scheme of the power system, in which the dual-BESS scheme has been incorporated. The portion of the figure with thicker lines corresponds to the power system model whereas the remaining portion corresponds to the control system. By adopting the conventional modeling approach in load-frequency control such as that described in [18], the generators in the grid are aggregated to form a single equivalent unit. The aggregated generator is represented simply as a first-order governor in cascade with a first-order turbine model, in which the time constants $\tau_{g}$ and $\tau_{T}$ have been introduced. The conventional droop setting is denoted by $r$. In addition, a ramp rate limiter is included to reflect the mechanical constraint on the rate of change of the governor. Also, electro-mechanical device is often insensitive to small signals to effect a change in its output. Therefore a dead-band is also included in the control scheme to account for this phenomenon. An additional control loop to account for the action of the BESS has been added. Time lag in the BESS is represented by the time constant $\tau_{B E S S}$. The Power and Energy Limiters associated with the BESS shall be described later.

Although not considered in this study, $\alpha_{1}$ and $\alpha_{2}$ are the respective participation factors of the BESS and conventional generators in secondary frequency control. This control mode is commanded by power system control center and in accordance to factors such as the amount of reserves, economic dispatch and ramp rate.

This paper only focuses on the primary control loop, and the associated control blocks are thus described as follows.

\subsection{Power limiters of the BESS}

The dual-BESS is designed for both power dispatching and frequency regulation applications. Therefore, the discharge power level of the BESS is:

$P_{b}=P_{D}+P_{d, f}$

where $P_{b}$ is the total output power of the BESS, $P_{D}$ is the scheduled power dispatch from the in-service BESS and $P_{d, f}$ is the discharged/charged power required to regulate system frequency.

Recall from Fig. 1 that the BESS is composed of a battery module and the associated discharging/charging converter. The maximum discharge/charge power of the BESS is constrained by the battery cell design and characteristics, as well as by the power capacity of the power converter designed for specific application. For normal power dispatch, typically for NaS battery considered in this study, the BESS is expected to operate at relatively steady power level for several hours [3]. The lifetime of the BESS can be estimated based on the number of full charge/discharge cycles the battery has undergone. For short duration pulse-type output power application, however, $\mathrm{NaS}$ battery is reported to be capable of supplying up to 5 times of its rated power for $30 \mathrm{~s}$ [19]. Therefore, it can be assumed that the $\mathrm{NaS}$ BESS maximum discharging/charging power level is much greater than the converter rating, if the discharge/ charge duration of interest is no more than $30 \mathrm{~s}$. The maximum charge/discharge power level must therefore be considered in conjunction with the ratings of the power converters connected to the battery modules.

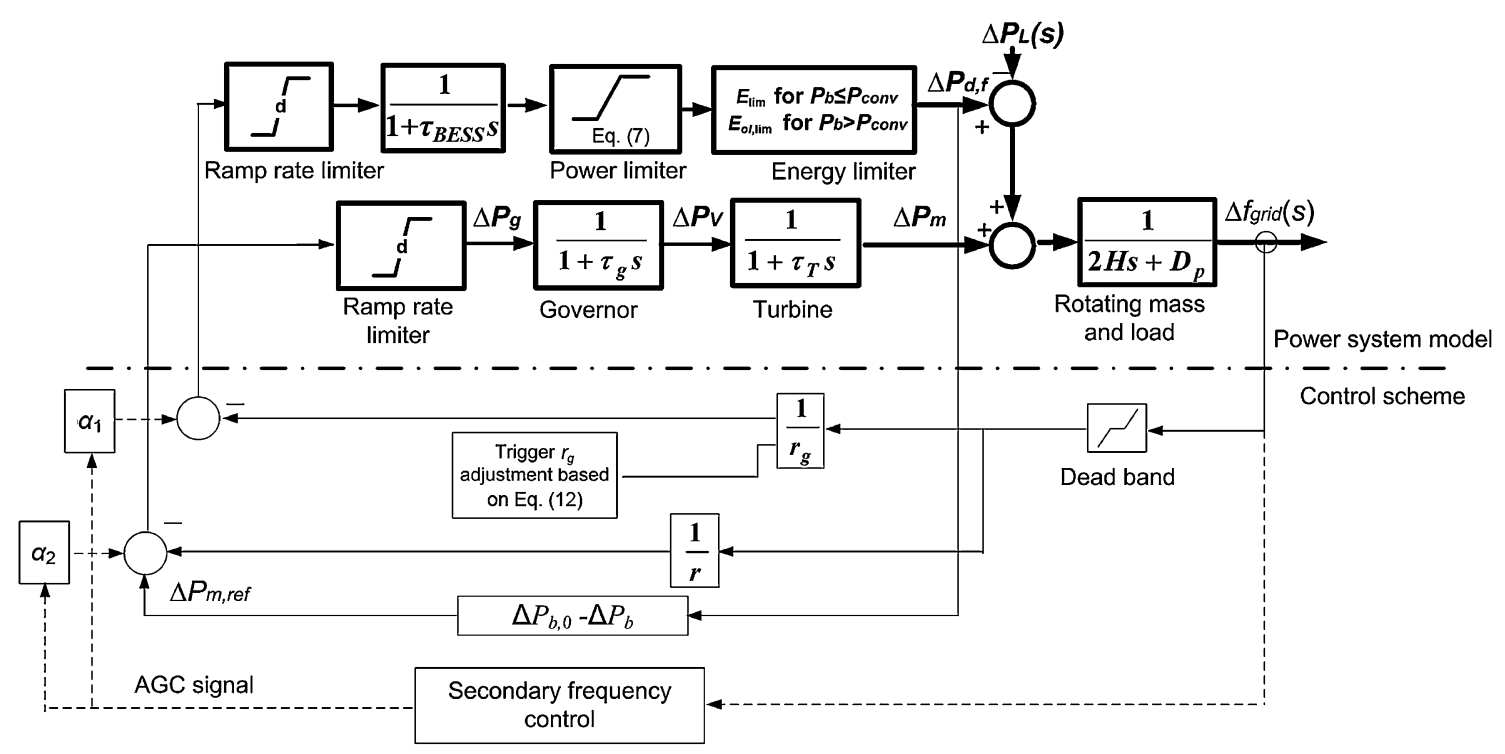

Fig. 3 Load-frequency regulation scheme with the inclusion of the dual-BESS 
The current and voltage ratings of the semiconductor switches in power converters are normally designed with some overloading capability [20]. Such capability, typically valid for up to $20 \mathrm{~s}$, is often given in the converter manufacturer's data sheet. The converter over-loading capability allows frequency regulation to be achieved through increasing the BESS charging/discharging power limit over a short duration. Thus the feasible operating range of $P_{b}$ should be determined by taking into consideration the duration of $P_{b}$.

In view of the above, for long-term dispatch operation, one can express $P_{b}$ to have limits

$P_{b} \in\left[-P_{c, \text { max }} \quad P_{d, \max }\right]$

In (2), $P_{c, \text { max }}$ and $P_{d, \text { max }}$ are the respective maximum charging and discharging powers of the BESS module. Since the maximum charge/discharge power is limited to match the converter power rating, denoted as $P_{c o n v}$, therefore,

$P_{c, \max }=P_{d, \max }=P_{c o n v}$

On the other hand, for short-duration (pulse-type) application,

$P_{b} \in\left[-P_{c o n v}-P_{o l} \quad P_{c o n v}+P_{o l}\right]$

In (4), $P_{o l}$ denotes the overloading capacity of the converter. As explained earlier, $P_{o l}$ is a function of the duration of the pulse. For example, the authors have conducted a survey to assess what would be the typical overloading capability of the selected inverters. Fig. 4 shows the overload capabilities of the selected inverters observed from [21-25] differ due to the differences in their design and applications, although there are some overlaps among curves. It can be observed from the survey that there are two common features in the specifications of the

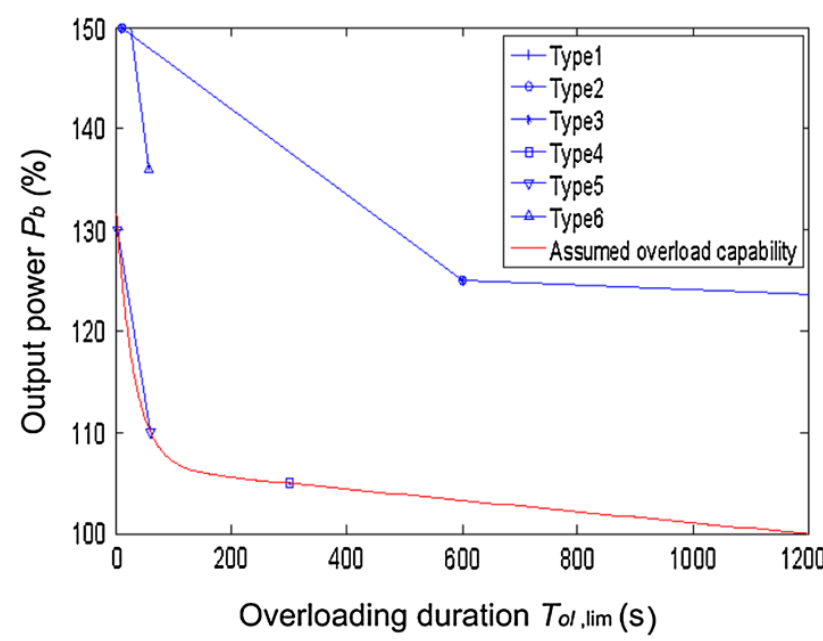

Fig. 4 Overloading capability limit curves of selected inverters inverters. Firstly, the inverters are designed to have a varying level of overload capability so that the reliability of the product can be increased, as has been considered in [20]. Secondly, the maximum withstand time for the overloading decreases with respect to the increase of overloading power.

To incorporate these observations on $P_{o l}$ into this study, a generic overload capability of inverter is assumed and this capability is shown by the curve labeled as "Assumed overload capability" in Fig. 4. The assumed curve is based on the lowest overload capability obtained in the survey and can be expressed in the following mathematical form:

$P=25.69 e^{-3.3263 \times 10^{-2} T_{o l, \text { lim }}}+106.7 e^{-5.42 \times 10^{-5} T_{o l, \text { lim }}}$

In (5a), $P$ is expressed in percentage of the converter rating and the overloading duration $T_{o l, l i m}$ is in second. As $P_{\text {conv }}$ denotes the converter rating, therefore

$P=P_{\text {conv }}+P_{o l}=\alpha_{o l} P_{\text {conv }}$

In $(5 b), \alpha_{o l}$ is defined as the overloading factor.

Equations (5a) and (5b) allow the authors to study the general overloading capability of converter incorporated in the dual-BESS scheme. Based on (2) and (3), the viable range of $P_{d, f}$ for dual-BESS long-duration operation can be stated as $P_{d, f} \in\left[-P_{c o n v}-P_{D} \quad P_{c o n v}-P_{D}\right]$

From (4) and for short-duration (pulse-type) operation, $P_{d, f}$ can be stated as

$P_{d, f} \in\left[-P_{c o n v}-P_{o l}-P_{D} \quad P_{c o n v}+P_{o l}-P_{D}\right]$

The last equation is as a consequence of the converter overloading capability expressed by (5b). The power limiter (7) therefore applies to BESS power flow control loop of Fig. 3 when frequency control action is initiated.

\subsection{Energy limiter}

The energy limiter in Fig. 3 is considered for two situations: inverter overloading and non-overloading periods. As shown in Fig. 4, the overloading capability of the inverter is only valid for a limited duration. In order to take both overloading power level and duration into consideration, an energy limiter must be included in the designed scheme. Also, even if the inverter is not overloaded, the BESS should not be continuously charged or discharged without bounds.

\subsubsection{Energy limit $\left(E_{\text {oll lim }}\right)$ during inverter overloading}

Incorporating an energy limiter into the control scheme under the inverter overloading condition is to reflect the overloading duration $T_{o l, \text { lim }}$ as a constraint. From Fig. 4, the maximum amount of energy $\left(E_{o l, \lim }\right)$ associated with 
the overloading capability of the inverter can be expressed in terms of the overloading power and overloading duration, as follows.

$E_{o l, \lim }=P_{o l} \times T_{o l, \lim }$

A typical $E_{o l, l i m}$ plotted against the overloading factor and duration is shown in Fig. 5. It is based on (5a). However, as shown in Fig. 5a, the energy limit depends on the overloading factor and in turn the power level. In this study, the strategy is to ramp down the BESS output during the overloading period before it reaches $T_{o l, \text { lim }}$, and after the system frequency has stabilized. An example is shown in Section 5 to illustrate this strategy.
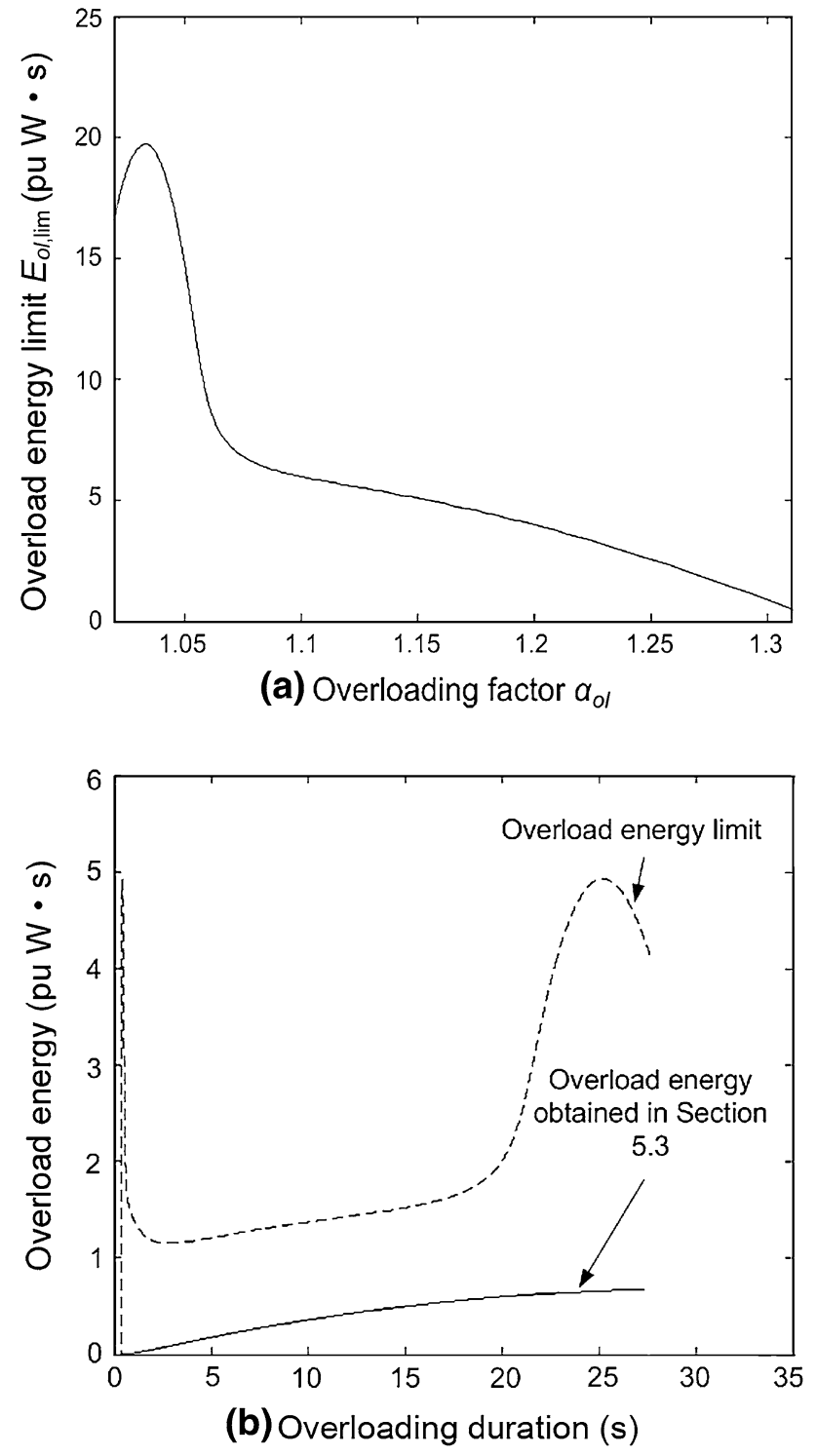

Fig. 5 (a) Overload energy limits plotted against the overloading factor $\alpha_{o l}$ (b) overloading duration

\subsubsection{Energy limit $\left(E_{\mathrm{lim}}\right)$ during inverter non-overloading period}

During the normal operation, the amount of stored energy in the battery used for frequency regulation should also be constrained. This is because a proportion of the stored energy in the dual-BESS scheme is to be used to achieve power dispatchability. Hence the energy level in the BESS should be maintained to satisfy the dispatch commitment which is determined by the method described in [3]. Also, a minimum amount of primary reserve $\left(E_{\mathrm{lim}}\right)$ is normally required under the grid code, for instance, 15 minutes under UCTE/ENTSO-e rule. For frequency control, charging/ discharging energy of the BESS during non-overloading period should therefore be controlled to the minimum level, subject to meeting the grid code requirement.

\subsubsection{Energy limiter settings}

In view of the above, the energy limiter shall be set according to the following conditions:

When $P_{b}>P_{\text {conv }}$, the energy limiter should be set to $E_{o l, l i m}$, which is calculated using (8). When the energy limit is violated, the output power of the battery shall be adjusted.

When $P_{b} \leq P_{\text {conv }}$, the energy limiter should be set to $E_{\text {lim }}$, which is described in Section 3.2.2. When the energy limit is violated, the output of battery power shall also be adjusted.

Section 3.3.2 shall explain how the battery output power can be adjusted.

\subsection{BESS droop setting $r_{g}$}

The BESS load-frequency control loop is added for the purpose of improving the network frequency regulation performance. As shown on Fig. 3, this loop involves the droop setting $r_{g}$. This section is pertaining to the selection of the value for $r_{g}$.

Consider the case of a generator trip. Since the BESS can be expected to respond much faster than the remaining on-line generating units to the resulting system frequency drop, the initial response of the overall power system shall be dominated by the BESS control loop. Suppose it is desirable for the steady-state frequency reduction following the generator trip is to be above a prescribed threshold value. However, due to the constrained over-loading capability of the BESS converter described earlier, the contribution from the BESS can only be sustained at high level for a limited period. Hence the manner by which the BESS subsequently reduces its output power should be based on the remaining on-line generators' ability to 
increase their output powers. The following section is to examine the extent of the control participation undertaken by the BESS through the judicious adjustment in $r_{g}$.

\subsubsection{Initial setting of $r_{g}$}

From Fig. 3 and by ignoring the initial contributions made by the remaining on-line generators, the steady-state frequency deviation at the setting of $r_{g}$ can be readily computed as

$\Delta w_{s s}=\left(-\Delta P_{L}\right) \frac{1}{D_{p}+1 / r_{g}}$

Therefore, the larger the value of $r_{g}$, the greater shall be the steady-state frequency deviation $\Delta w_{s s}$. Suppose $\Delta w_{s s}$ is to be controlled to be less than a pre-set limit $\Delta w_{s s, l i m}$ through this primary frequency control loop. Also assume the worst-case scenario of a power imbalance $\Delta P_{L}$ of (say) $P_{x}$ pu. A practice often used by utility in designing loadfrequency control is for $\Delta P_{L}$ to correspond to the tripping of the largest on-line unit in the power system. Then from (9), it can be readily seen that $r_{g}$ must not exceed the value of $r_{g, 0}$ where

$r_{g, 0}=1 /\left(\frac{-P_{x}}{\Delta w_{s s, \lim }}-D_{p}\right)$

As a guide, $r_{g}$ may therefore be set at the value of $r_{g, 0}$ as (10) guarantees that $\Delta w_{s s}$ shall not exceed $\Delta w_{s s, \text { lim }}$ under the considered worst-case scenario.

Alternatively, the initial setting of $r_{g}$ could be determined to ensure that the frequency deviations shall not trigger any under-frequency load shedding (UFLS) incident. The generation-load imbalance can be modeled as a step change $\Delta P_{L}$ and the system response can be analyzed in the time-domain. The frequency excursions shall be checked against the trigger setting of UFLS. This approach shall be illustrated in a numerical example in Section 5.

\subsubsection{Adjustment of $r_{g}$}

As explained earlier, the battery output power must be adjusted if the converter power and/or energy capacity limits are reached. Even if the limits have not been reached and the frequency drop has been arrested, it is desirable to reduce the BESS output power if the BESS is overloaded. The adjustment in the BESS output power can be achieved by increasing $r_{g}$ to reduce the BESS contribution to the frequency regulation. Conversely, if the battery energy and power levels are within the allowable ranges but $r_{g}>r_{g, 0}$, $r_{g}$ should be reduced. This can be readily seen from Fig. 3: decreasing $r_{g}$ causes the proportion of the power contribution from the BESS to increase.

As $r_{g}$ changes and the BESS adjusts its output power after the initial period, the generators shall then respond by adjusting their output powers to compensate for the BESS output power change. To meet this requirement, the rate of change of $1 / r_{g}$ must not exceed the maximum output power ramp up/down rate of the generators. Let $\alpha$ denotes the rate of change of $1 / r_{g}$, thus $\alpha$ must satisfy the condition

$\alpha \leq\left(1 / r_{g, 0}\right) / T_{\min }$

In (11a),

$T_{\min }=\frac{P_{x}}{\lambda_{\max }}$

where $\lambda_{\max }$ is the maximum ramp rate of the generators.

$r_{g}$ may be adjusted in steps: $r_{g}(k)$ at the $k$ th step is

$\frac{1}{r_{g}(k)}=\left\{\begin{array}{lll}\frac{1}{r_{g}(k-1)}+\alpha \Delta t, & \text { if } & \text { (a) } \\ \frac{1}{r_{g}(k-1)}-\alpha \Delta t, & \text { if } & \text { (b) }\end{array}\right.$

where, (a) battery contribution is to increase; and (b) battery contribution is to decrease; $r_{g}(0)=r_{g, 0}$ and $\Delta t$ is the interval between two consecutive adjustments.

The above concept can be further illustrated using Fig. 6: Upon the onset of the generator trip, the BESS output power pulses up rapidly to a value $\Delta P_{b, 0}$. Note that $\Delta P_{b, 0}$ corresponds only to the change in the $P_{d, f}$ component of $P_{b}$. Subsequently, the output of BESS is to decrease at the ramp-down rate $\alpha$ as shown in Fig. 6 through adjusting $1 / r_{g}$. The decrease in $\Delta P_{b}$ shall be met by the corresponding increase $\Delta P_{m}$ in the generators' output. Fig. 6 shows the reference signal $\Delta P_{m, r e f}$ for $\Delta P_{m}$ is generated such that $\Delta P_{m, r e f}=\Delta P_{b, 0}-\Delta P_{b}$. To avoid any possible adverse control outcome due to the generators' inability to make up for the decrease in $\Delta P_{b}$, ramping-down time from $\Delta P_{b, 0}$ to $\Delta P_{b} \approx 0$ should not be shorter than $T_{\min }$. Therefore, $\alpha$ can be determined based on (11a). As shown in (11b), $T_{\min }$ is calculated based on the worst case scenario when at the end of the primary frequency control stage, $P_{x}$ shall be picked up by the remaining on-line generators and not the BESS.

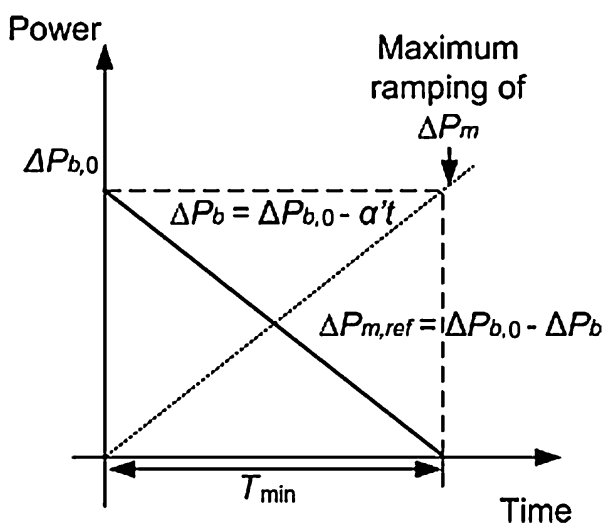

Fig. 6 Ramp down of BESS output power 
Next, consider the closed-loop transfer function when ignoring the boundaries set by the limits, and when only the BESS is undertaking the frequency regulation function:

$$
\begin{aligned}
\frac{\Delta f_{\text {grid }}}{\Delta P_{L}} & =\frac{-\frac{1}{\left(2 H s+D_{p}\right)}}{1+\frac{1}{r_{g}\left(2 H s+D_{p}\right)\left(\tau_{B E S S} s+1\right)}} \\
& =-\frac{r_{g} \tau_{B E S S} s+r_{g}}{2 r_{g} H \tau_{B E S S} s^{2}+r_{g} \tau_{B E S S} D_{p} s+2 r_{g} H s+r_{g} D_{p}+1}
\end{aligned}
$$

Based on Routh-Hurwitz analysis, the closed-loop system is seen to be stable if $r_{g}$ is positive.

\subsubsection{Control of $\Delta P_{m}$}

As the BESS adjusts its output power, the corresponding regulation in $\Delta P_{m}$ is through the manipulation in the power reference level $\Delta P_{m, r e f}$ for the generators. As shown in Fig. 3, $\Delta P_{m, r e f}$ is an additional control signal on the generators, and it is fed to the same summing junction where the conventional frequency droop control is effected.

Under the normal condition described under Section 3.2.2 in which the BESS converter overloading has not occurred, of course, $\Delta P_{m, r e f}=0$.

\section{Analysis on reducing the required capacity of converter based on its overloading capability}

This section is to illustrate that the required capacity of the converters can be effectively reduced by taking its overloading capability into the problem formulation.

As described in Section 3.1, if there is no additional grid code requirement on power dispatching, the dispatch power limits of the dual-BESS are set by the rating of the DC/AC converters i.e. the converter is allowed to operate within the range $\left[0, P_{c o n v}\right]$, where $P_{c o n v}$ is the power rating of the converter.

\subsection{Without considering converter overloading}

If the overloading capability is not considered, the dualBESS is not able to support frequency regulation when dispatching power at the rated value, and converters are not oversized. If the average system demand is $1 \mathrm{pu}$ and the aggregated rating of the dual-BESS scheme is $\alpha_{\text {bess }}$ pu. Since load demand is time-varying and random, it would be appropriate to quantify load in statistical term. Suppose load variations are assumed to follow a normal distribution with variance of $\sigma$. The range [-3 $\sigma \mathrm{pu}, 3 \sigma \mathrm{pu}]$ covers $99.9 \%$ of the possible load variations. Hence, to achieve 0.999 probability of meeting the load demand by the wind farmdual BESS scheme under the maximum power dispatch scenarios, the converter should be up-sized at the very least by a factor $\beta$ such that

$\alpha_{\text {bess }} \times \beta=3 \sigma \Rightarrow \beta=\frac{3 \sigma}{\alpha_{\text {bess }}}$

Using the numerical example shown in Section 5, $\alpha_{\text {bess }}=0.25$, and assume $\sigma=0.01, \beta=0.12$. That is, the converter should be up-sized by $12 \%$ to meet the requirements.

\subsection{With overloading capability considered}

If the overloading capability of power converter $P_{o l}=20 \%$, it is not necessary to up-size the converter since $\beta \leq 0.2$. If $\beta>0.2$, the converter should only need to be up-sized by the factor $\beta-0.2$.

\section{Illustrated examples}

As explained in Section 3, often the power system is designed to contain frequency excursion following the tripping of the largest on-line generating unit. This example serves to illustrate the use of the dual-BESS scheme to meet this requirement. Suppose $P_{x}=0.05 \mathrm{pu}$. System parameters obtained from $[18,26]$ are used: $\tau_{T}=0.5 \mathrm{~s}$, $\tau_{g}=0.2 \mathrm{~s}, D_{p}=0.8 \mathrm{pu} \mathrm{MW} / \mathrm{Hz}, r=0.05$. Thermal generators are assumed subject to a ramp rate limit of $\pm 0.17 \%$ pu MW/s [19] (expressed in terms of the units' power ratings).

\subsection{Determination of $r_{g, 0}$}

Also from [9], the authors have specified a non-critical frequency window in the form of a frequency deviation dead-band within which no primary frequency regulation is to function. Specifically, the dead-band is set at \pm 0.001 $\mathrm{pu}$, a level which is also adopted in this example. Steadystate frequency deviation limit $\Delta w_{s s, \text { lim }}$ is assumed to be $0.004 \mathrm{pu} \mathrm{Hz}$. The base frequency is $50 \mathrm{~Hz}$. It is used to determine the initial setting $r_{g, 0}$. By applying (10), it is seen that

$r_{g, 0} \leq 0.0812 \mathrm{pu} \mathrm{Hz} / \mathrm{pu} \mathrm{MW}$

Therefore, $r_{g, 0}$ could be set at $0.08 \mathrm{pu} \mathrm{Hz} / \mathrm{pu}$ MW. However, as explained in Section 3.3.1, the suitability of this setting should be evaluated further in case of violating UFLS frequency setting threshold, as follows.

Let $\Delta P_{L}$ be a step change of $P_{x}=0.05 \mathrm{pu}$, where the total installed capacity is taken as $1 \mathrm{pu}$. Substituting the known values of $\tau_{B E S S}, H$ and $D_{p}$ into (13) and setting $r_{g, 0}=0.08$, inverse Laplace yields 
Fig. 7 (a) Frequency deviations with the integration of BESS. (b) Output of BESS. (c) Output of thermal generators. (d) Profile of $1 / r_{g}$ following the generator trip at $t=0$

$$
\begin{aligned}
\Delta f_{\text {grid }}(t)= & -0.0037594-0.00012496 \mathrm{e}^{-8.51874 t} \\
& +0.00388436 \mathrm{e}^{-1.56126 t}
\end{aligned}
$$

The minimum value of $\Delta f_{\text {grid }}(t)$ is $-0.0037 \mathrm{pu}$. If the first stage UFLS frequency setting is $-0.02 \mathrm{pu}$, a value which is quite typical in power systems [18], the selected $r_{g, 0}=0.08 \mathrm{pu} \mathrm{Hz} / \mathrm{pu} \mathrm{MW}$ in this example will be quite suitable as it will prevent any load shedding event from occurring. If this condition is not met, then $r_{g, 0}$ should be reduced until the UFLS event can be avoided.

\subsection{Determination of $\alpha, E_{\text {lim }}$ and limits on $P_{d, f}$}

Next, suppose the average load demand is $1 \mathrm{pu}$ and the wind generation supplies $10 \%$ of the demand on average. Assume the wind output power corresponds to $40 \%$ of the installed capacity of the wind generation. Hence, $P_{\text {conv }}=1 \times 10 \% / 40 \%=0.25 \mathrm{pu}$.

Since wind generation supplies $10 \%$ of the demand on average, the remaining $90 \%$ of the load demand is supplied by other thermal generators. Assume these generators operate at $90 \%$ of their rating $P_{g \text {,rated }}$. Hence, $P_{g \text {,rated }}=$ $1 \times 90 \% / 90 \%=1 \mathrm{pu}$. The ramp rate limit of these thermal units is therefore $\pm 0.0017 \mathrm{pu} \mathrm{MW/s}$.

The appropriate rate of change of $1 / r_{g}$ is calculated by the method describe in Section 3.3. The minimum elapsed time for the thermal units to pick up the sudden $0.05 \mathrm{pu}$ loss of generation is $0.05 / 0.0017$ or $29.4 \mathrm{~s}$. Include a safety margin into the design, (say) the thermal unit pick-up time of $35 \mathrm{~s}$, and since $r_{g, 0}=0.08$, from (11) and (12), $1 / r_{g}$ is set to change at the rate $\alpha=1 /(0.08 \times 35)=0.3571 \mathrm{pu}$ $\mathrm{MW} / \mathrm{s}$. In this way, it will take $35 \mathrm{~s}$ for the battery output to reduce from its initial loading level value to zero.

As explained in Section 2.1, in some countries, the primary frequency control should be able to sustain for $15 \mathrm{~min}$. Therefore, in this example, the energy limit $E_{\text {lim }}$ is set as $0.05 \times 60 \times 15 \mathrm{pu} \mathrm{MW} \cdot \mathrm{s}=45 \mathrm{pu} \mathrm{MW} \cdot \mathrm{s}$.

The worst case is when the dispatched power has already reached the converter rating, i.e. $P_{D}=P_{\text {conv }}$. In this instance, the converter should only be overloaded for a short while. However, from (7), the discharge power to regulate frequency in the initial moment shall be within the range:

$P_{d, f} \in\left[-2 P_{c o n v}-P_{o l} \quad P_{o l}\right]$

Substituting $P_{c o n v}=0.25 \mathrm{pu}$ and $P_{o l}=20 \% \times 0.25$ $\mathrm{pu}=0.05 \mathrm{pu}$ into (15), the limits on the frequency regulation power component $P_{d, f}$ are $[-0.55,0.05]$.

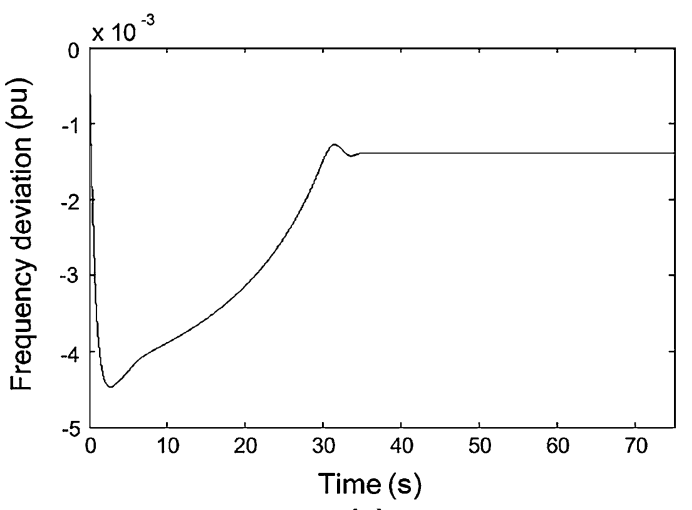

(a)

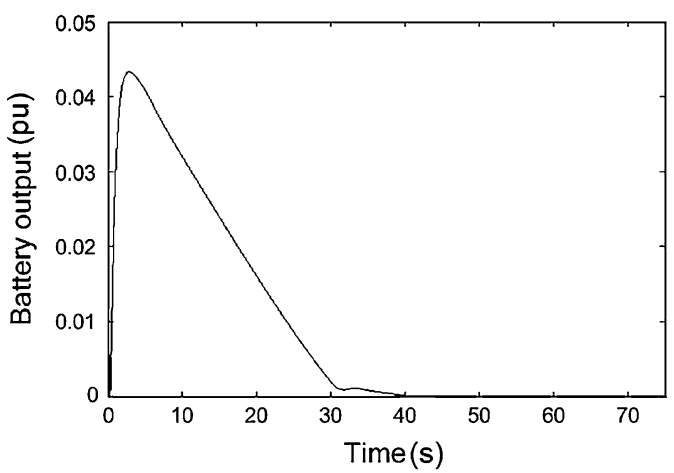

(b)

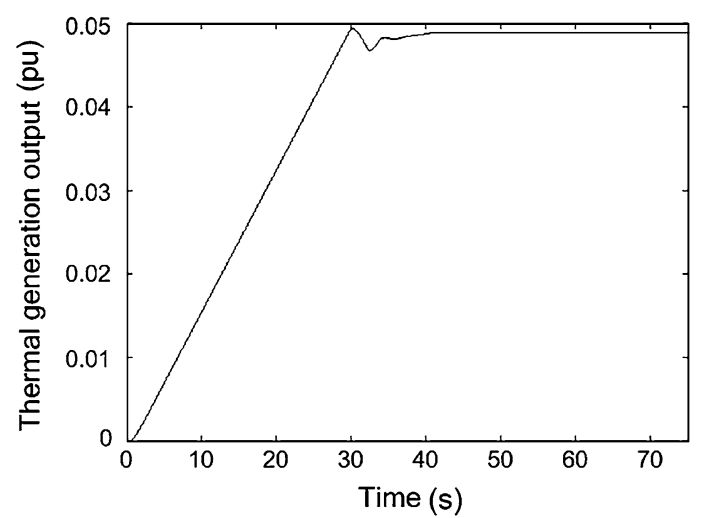

(c)

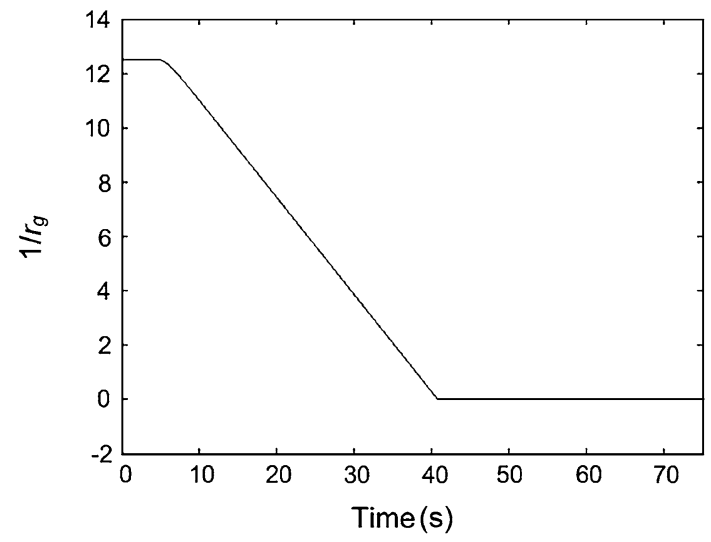

(d) 


\subsection{Dynamic simulation}

Following the sudden 0.05 pu generation trip, the BESS can help to support network frequency by forcing its converter to operate at its overloading limits. Simulation study has been carried out to illustrate this strategy and the obtained results are as shown in Fig. 7.

Within five seconds following the generator trip, the fall in frequency (Fig. 7a) has been arrested but the battery output has to be reduced because the converter power limit is reached. The reduction in the battery output power is then picked up by the thermal generators. These operations are shown in Fig. $7 \mathrm{~b}$ and $7 \mathrm{c}$ respectively. $1 / r_{g}$ changes in a linear manner, as illustrated in Fig. 7d.

During the stage when the overloading capability of the BESS module is utilized, the corresponding energy profile can be obtained by interpolating the curve in Fig. 5a. Comparing the overload energy limits (shown as dotted

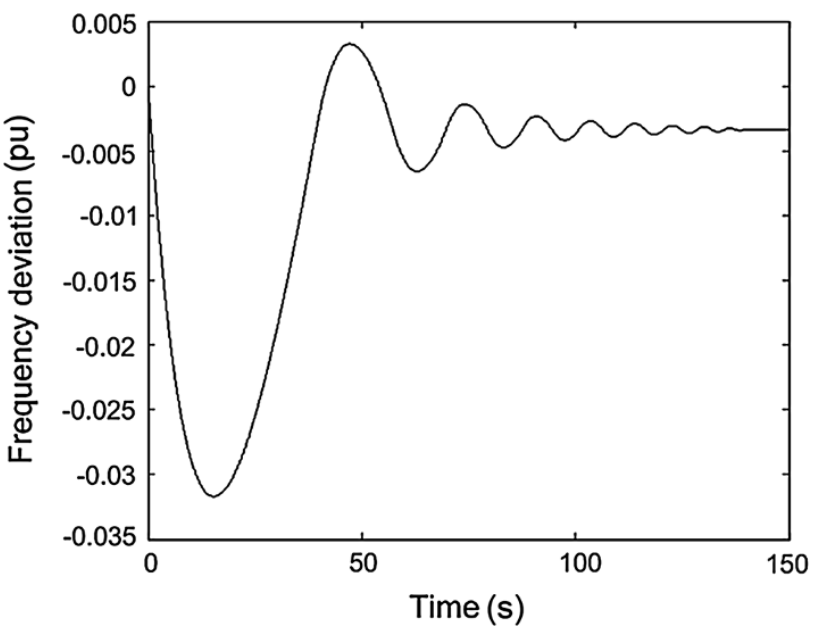

(a)

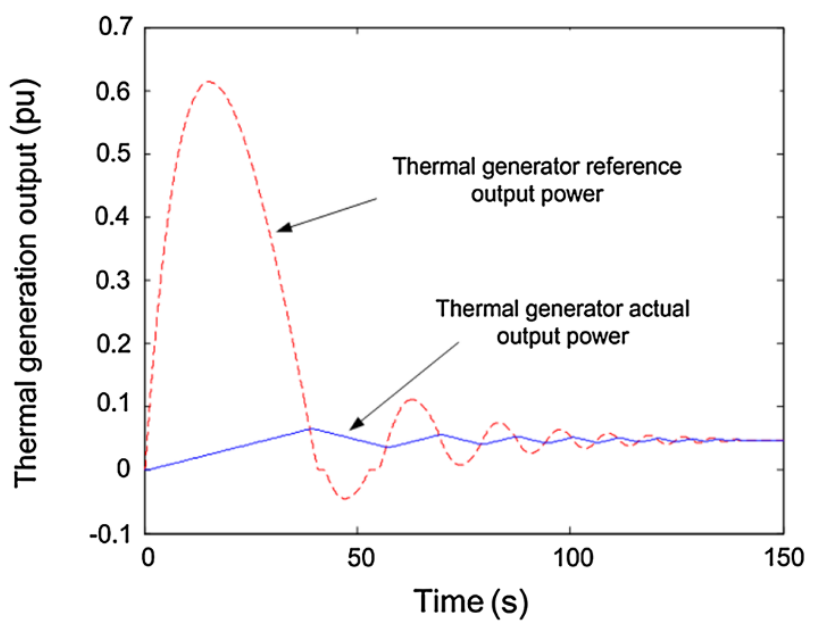

(b)

Fig. 8 (a) System frequency deviation without the BESS. (b) Thermal generation output without the BESS line in Fig. 5b with the overload energy (solid line in the same figure), it shows that the proposed strategy to adjust $r_{g}$ is prudent for this application. This is because the strategy has not resulted in the overload energy limit being breached.

Comparing the frequency deviation with that of the case when the BESS is not in use, as shown in Fig. 8a, it is not surprising to note that the frequency deviation has indeed been significantly reduced. The large variations in system frequency observed in Fig. 8a are due to the ramp-up and ramp-down limits of the thermal generators. The ramp rate limits of the thermal generators also prolong the damping time of the frequency deviations. Based on the proposed control scheme, when there is a frequency deviation in the system, a signal will be sent to the thermal units as their reference/target output power. As illustrated in Fig. 8b, the actual output of generator cannot track the reference signal. Therefore, it demonstrates that the dual-BESS scheme is indeed effective in improving the performance of network frequency regulation.

\section{Conclusions}

The frequency regulation ancillary function of the dualBESS scheme [3] has been proposed in this paper. It makes use of the fast-response characteristic of BESS for primary frequency control, to match with the control of conventional generators in which their ramping up/down rates are physically constrained. The overloading capability of the converter can be included into the design of control scheme which enables the capacity of converter to be minimized. Numerical results have shown that the dual-BESS scheme is beneficial in providing frequency support, as part of the network ancillary service.

Open Access This article is distributed under the terms of the Creative Commons Attribution License which permits any use, distribution, and reproduction in any medium, provided the original author(s) and the source are credited.

\section{References}

[1] Rebours YG, Kirschen DS, Trotignon M et al (2007) A survey of frequency and voltage control ancillary services-Part II: economic features. IEEE Trans Power Syst 22(1):358-366

[2] Rebours YG, Kirschen DS, Trotignon M et al (2007) A survey of frequency and voltage control ancillary services-Part I: Technical features. IEEE Trans Power Syst 22(1):350-357

[3] Yao DL, Choi SS, Tseng KJ et al (2012) Determination of shortterm power dispatch schedule for a wind farm incorporated with dual-battery energy storage scheme. IEEE Trans Sustain Energy 3(1):74-84

[4] Yao DL, Choi SS, Tseng KJ et al (2010) Determination of a dispatch strategy to maximize income for a wind turbine-BESS 
power station. In: Proceedings of the international power and energy conference (IPEC'10), Singapore, 27-29 Oct 2010, 6p

[5] Yao DL, Choi SS, Tseng KJ et al (2012) Dynamic study of a battery change-over scheme of a wind farm containing dual BESS. In: Proceedings of the international power and energy conference (IPEC'12), Ho Chi Minh City, Vietnam, 12-14 Dec 2012, 7p

[6] Aditya SK, Das D (2001) Battery energy storage for load frequency control of an interconnected power system. Electr Power Syst Res 58(3):179-185

[7] Lu CF, Liu CC, Wu CJ (1995) Effect of battery energy storage system on load frequency control considering governor deadband and generation rate constraint. IEEE Trans Energy Conver 10(3):555-561

[8] Mercier P, Cherkaoui R, Oudalov A (2009) Optimizing a battery energy storage system for frequency control application in an isolated power system. IEEE Trans Power Syst 24(3):1469-1477

[9] Oudalov A, Chartouni D, Ohler C (2007) Optimizing a battery energy storage system for primary frequency control. IEEE Trans Power Syst 22(3):1259-1266

[10] Sekyung H, Soohee H, Sezaki K (2010) Development of an optimal vehicle-to-grid aggregator for frequency regulation. IEEE Trans Smart Grid 1(1):65-72

[11] Goya T, Omine E, Kinjyo Y et al (2011) Frequency control in isolated island by using parallel operated battery systems applying $\mathrm{H} \infty$ control theory based on droop characteristics. IET Renew Power Gener 5(2):160-166

[12] Oudalov A, Chartouni D, Ohler C et al (2006) Value analysis of battery energy storage applications in power systems. In: Proceedings of the 2006 IEEE PES power systems conference and exposition (PSCE'06), Atlanta, GA, USA, 2206-2211 29 Oct-1 Nov 2006

[13] Žertek A, Verbič G, Pantoš M (2012) Optimised control approach for frequency-control contribution of variable speed wind turbines. IET Renew Power Gener 6(1):17-23

[14] Teninge A, Jecu C, Roye D et al (2009) Contribution to frequency control through wind turbine inertial energy storage. IET Renew Power Gener 3(3):358-370

[15] Zhang ZS, Sun YZ, Lin J et al (2012) Coordinated frequency regulation by doubly fed induction generator-based wind power plants. IET Renew Power Gener 6(1):38-47

[16] Keung PK, Li P, Banakar H et al (2009) Kinetic energy of windturbine generators for system frequency support. IEEE Trans Power Syst 24(1):279-287

[17] Ma HT, Chowdhury BT (2010) Working towards frequency regulation with wind plants: combined control approaches. IET Renew Power Gener 4(4):308-316

[18] Bevrani H, Hiyama T (2011) Intelligent automatic generation control. CRC Press, Boca Raton, FL, USA

[19] Nichols DK, Eckroad S (2003) Utility-scale application of sodium sulfur battery. In: Proceedings of the 7th annual international stationary battery conference (Battcon'03), Marco Island, FL, USA, 28-30 Apr 2003, 9p

[20] Sugawara Y, Ogata S, Izumi T et al (2009) Development of a $100 \mathrm{kVA} \mathrm{SiC}$ inverter with high overload capability of $300 \mathrm{kVA}$.
In: Proceedings of the international symposium on power semiconductor devices and IC's (ISPSD'09), Barcelona, Spain, 14-18 Jun 2009, 4p

[21] Industrial AC and DC drives. http://www.hmkdirect.com/ products/drives/inverter/siemens_micromaster_mm440/. Accessed 2012

[22] Statron IDS and IDT range of inverters with single phase or three phase output using advanced digital control technology for userfriendly operation flexible interfaces. http://www.medltec. ru/IDS-IDT\%20Wechselrichter\%20E.pdf. Accessed 2000

[23] ASTRID Saturm 3/3-40 6080 kVA UPS 100125 technical data sheet. http://www.astrid.hk/download/AI_Tech_40-60-80-100125_3p3p.pd. Accessed 2012

[24] MicroGram computers. http://www.mgram.com.au/pdf/1008155. pdf. Accessed 2012

[25] Powerware series: Eaton 5110 UPS. http://lit.powerware.com/l1 download.asp?file $=5110 \% 20$ datasheet $\% 20$ rev\%20B.pdf. Accessed 2011

[26] Saadat H (2004) Power system analysis. McGraw-Hill, Singapore

Dailin YAO received her B.E. degree in Electrical Engineering from Wuhan University, Hubei, China in 2007. She then received her M.Sc. and $\mathrm{PhD}$ degrees in Power Engineering from Nanyang Technological University, Singapore in 2008 and 2013 respectively. Her research interests are in energy storage systems, power system control and renewable energy systems.

San Shing CHOI received his B.E. and Ph.D. degrees from the University of Canterbury, New Zealand in 1973 and 1976, respectively. He had worked in the New Zealand Electricity Department, National University of Singapore and the State Energy Commission of Western Australia. Dr. Choi is now a Professor in the School of Electrical and Electronic Engineering, Nanyang Technological University, Singapore. His research interests are in power quality, power system control and renewable energy systems.

King JET TSENG was born in Singapore. He received the B.Eng. (First Class) and M.Eng. degrees from the National University of Singapore, Singapore, and the Ph.D. degree from Cambridge University, Cambridge, U.K. He is currently the Head of Power Engineering Division at the School of Electrical and Electronic Engineering, Nanyang Technological University, Singapore. He teaches electrical power engineering and power electronics at both undergraduate and postgraduate levels, and manages a number of research programs in the area of electrical energy and power.

Tek TJING LIE received his B.S. degree from Oklahoma State University, USA in 1986. He then obtained his M.S. and Ph.D. degrees from Michigan State University, USA in 1988 and 1992, respectively. He had worked in Nanyang Technological University, Singapore. Dr. Lie is now a Professor and Head of Dept. of Electrical and Electronic Engineering, Auckland University of Technology, New Zealand. His research interests include power system control, deregulated power systems and renewable energy systems. 